MATEC Web of Conferences 22,04025 (2015)

DOI: $10.1051 /$ matecconf/ 20152204025

(C) Owned by the authors, published by EDP Sciences, 2015

\title{
Tectonic Characteristics and its Effects on the Control of the Oil and Gas Accumulation in Bayanhushu Depression
}

\author{
Zhaobin Tan \\ College of Geoscience, Northeast Petroleum University, Daqing, Heilongjiang, China \\ $\mathrm{Xi} \mathrm{Lu}$ \\ College of Economics and Management, Northeast Petroleum University, Daqing, Heilongjiang, China \\ Tianqi Zhao \\ College of Geoscience, Northeast Petroleum University, Daqing, Heilongjiang, China
}

\begin{abstract}
In this paper, it makes full use of seismic and Wells in the single well data on the basis of predecessors' research. On the basis of structural geology theory as the instruction, the detailed characteristics of structure and fracture were studied in this paper. Based on the fracture characteristics, the authors studied the basement depth and the development of hydrocarbon source rocks characteristics, and the restoration method of sag tectonic evolution characteristics are analyzed as well. The authors also discussed the construction control of the oil and gas distribution rules. Through this research, the authors found out the regional tectonic framework, the fault distribution and the tectonic evolution stage, illustrated the structure of oil and gas accumulation conditions, the accumulation mode, and the distribution rule of control law. Through prototype basin restoration, the authors given concerns about the early depression and tectonic background of stuck faults control source, the distribution of sand body, the western steep slope fan delta and gentle slope belt of eastern braided river delta front sand body is favorable reservoir. Depression after Nantun group and the end of the Yimin group at the end of the reversal of the two big changes, ring between the concave structure development, favorable traps formed early reverse changes, late reverse change on the early formation of trap destruction; reservoir by the late Nantun group is formed by the reverse change control in the construction of the steep slope belt wing structure oil and gas enrichment.
\end{abstract}

Keywords: Bayanhushu depression; structural characteristics and tectonic evolution of fault; distribution of oil and gas

\section{INTRODUCTION}

The Bayanhushu depression SAR stands southwestern Inner Mongolia Autonomous Region Hulunbeier New Barag Right Banner, north wood Hal, Keer Lun south, east to New Barag Right Banner, west of the Mongolian border, longitude $115^{\circ} 33^{\prime}-116^{\circ} 37^{\prime}$, latitude $48^{\circ} 03^{\prime}-48^{\circ} 43^{\prime}$. Structure located Hailar Basin Zhalainuoer Depression southwest, an area of approximately $1500 \mathrm{~km}^{2}$, basal maximum burial depth of about $5300 \mathrm{~m}^{[1]}$.

The Bayanhushu depression with narrower "S" shape was wide on the central plane, , the aspect ratio is in a range of $1: 4$ to $1: 6$, and the NE trending structure which is near 450 to 550 , is steeply NW, SE slowly the asymmetric single off-type structure. The Bayanhushu depression formation can be divided into three sequences. Which Xing'anling Group Tamulangou formations common development in the region, according to the times can be divided three separated sequences. The bottom boundary is reflective layer $T_{5}$. The top of $\mathrm{T}_{4}$ screen is a reflective layer, both of which are angular unconformity surface, and the upper and lower boundaries clear.

Bayanhushu depression belong rift depression in a small basin, complex geological conditions, the structure has a fault complex fracture of times more, bend down conversion and fast; Have deposited near source, multi-provenance, sedimentary facies change quickness. Structural control of the deposition, reservoir-cover conditions, but also to control the oil and gas migration and accumulation conditions, the ultimate control of the oil and gas distribution. Research undoubtedly strengthen structural basis for assessing research in areas of oil and gas resources. Bayanhushu depression is NNE-trending axis, an area of approximately $1500 \mathrm{~km}^{2}$, basal maximum burial depth of about $5300 \mathrm{~m}$. Provides a more seismic exploration work of the depression mainly 1998 , made in 2008 , to the end of 2008, a total of two-dimensional seismic coverage over approximately $1500 \mathrm{~km}$, the district has drilled seven exploration wells, seismic geological interpretation, structural features anatomical depression rich biography. 


\section{MATEC Web of Conferences}

\section{FRACTURE CHARACTERISTICS}

Bayanhushu depression have normal faults, most of the faults are consistent with the axial depression, namely NE direction, and there is a small amount of $\mathrm{NS}$, and the NEE trending faults that is ranging from $10 \mathrm{~m}$ to $600 \mathrm{~m}$. Both large regional uplift and erosion areas are stably deep depression trough area, that the complexity of reverse fault zone. There are simple monoclinic occurrence areas, construct strong differentiation, but structure looks more complicated. Settlement of the Israeli-Palestinian subsags deposition center in Sag main tank formations from depression east and west sides gradually lifted, the west border with the same deposition adun $\mathrm{Chu} \mathrm{Lu}$ fault is bounded by boundary formation faulting and depositing a greater impact, occurrence is more complex; in the east ramp area, fault occurrence changes relatively stable; depression-slope transition zone of active tectonic activity, the formation of low-amplitude inverted slightly elevated and parallel to the gentle slope into the strip ${ }^{[2-4]}$.

Judging from the seismic profiles, Bayanhushu depression fault development, boundary faults shovel normal faults, other secondary faults in a straight-based, inter-block with a stepped base graben portfolio or portfolio-based (Figure 1). Distribution regularity strong fracture zone, according to the direction of the plane distribution point of view, the region I, II grade scale fracture to the NE and NNE towards the main western border adun $\mathrm{Chu} \mathrm{Lu}$ fault and its associated with two steps to the east fault and B9, B15 number of such faults are faults adun $\mathrm{Chu} \mathrm{Lu}$ fault and fault of control number B9 Tongbomiao with structural and sedimentary distribution. II grade fault zone in larger quantities, mainly to NE trending faults, they are almost parallel to the south, and the north boundary fault depression groove. According to the direction of fracture plane distribution is divided into three groups: NE direction, NNE or near NS direction and the direction of the fracture system.

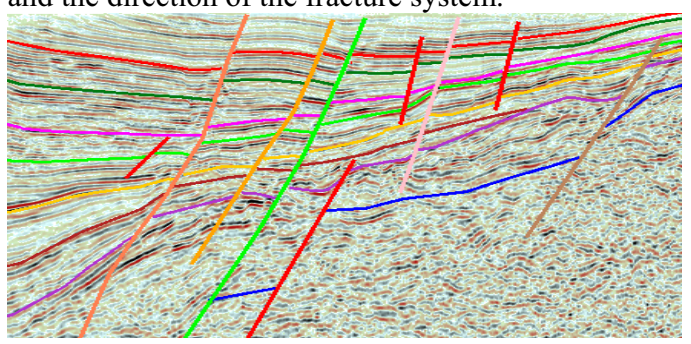

Figure 1. Bayanhushu fault depression stepped combination typical profile

\section{STRUCTURAL FEATURES}

\subsection{Structural Styles}

Structural style is to express all kinds of combinations of structural basin geometry, depending on the combination of its construction style, which can determine the mechanical mechanism of depression, and then predicting the tectonic and depositional model for seismic structural interpretation provided structural model. Constructing a combination of different structural styles has a certain development law, which determines the formation and distribution of oil and gas structural traps. So structural style is connected background sedimentary basin analysis and local deformation mechanisms accumulation elements of the bridge and link.

Bayanhushu depression manifested as graben fault characteristics overall, its dynamic background is simple, as a more typical type in extensional tectonic activities. Performance in its construction style, it can be basically divided into three categories: simple stretching, inversion and composite structural style, and especially extensional tectonic style. Extensional tectonic style concrete can be subdivided into normal faults reversing traction, tilted fault block in the same direction, reverse tilt block, such as a combination of base graben block pattern (Figure 2, Figure 3).

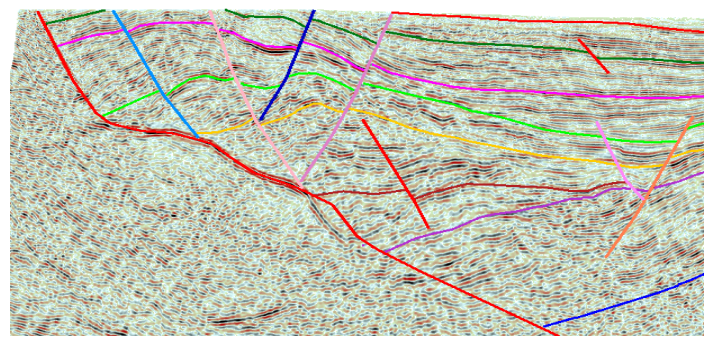

Figure 2. Bayanhushu gentle slope with typical seismic profiles (Y-shaped, stepped combination)

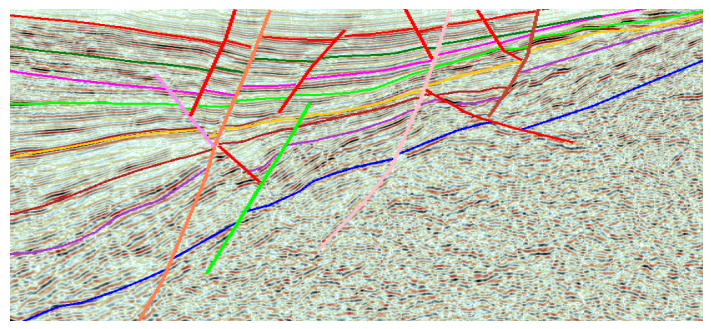

Figure 3. Bayanhushu steep depression with typical seismic profile (traction anticline)

\subsection{Tectonic Evolution Analysis}

The analysis for the tectonic evolution of this study is mainly based on three aspects: (1) analysis and acoustic stratigraphy of each period to calculate the residual thickness of stripping appetite; (2) the tectonic evolution of the profile analysis; (3) analysis of tectonic evolution and history of the development of the adjacent. The analysis of these three aspects of the tectonic evolution in this study is mainly divided into three stages: stage rift (which is from Jurassic to Tong- 
bomiao deposition period), Au off period (Nantun set off a period of depression $\sim$ yimin groups during the deposition), and depression stage (upper Cretaceous sedimentary period).

The study found Bayanhushu depression in the western steep is a significant interbasin-tectonics ${ }^{[5-7]}$. Therefore, we reverse the characteristic of structure in this study, and the inversion-tectonics refers to the history of the development process. The tectonic stress in opposite directions at different times is on the same geological body joint, superposition of structural features. Therefore, it is also known as a basin-inversion or structural-inversion. It is also becoming a major factor affecting the depressed oil and gas enrichment, it is worth to be explored. Bayanhushu depression experienced at least two distinct activities of interbasin-tectonics. In the end of the Nantun and Late Cretaceous, the impact of this construction activity on depression steep structural belt is obvious, so they are uplifted and denudate.

\subsection{Evolutionary stage of division}

The tectonic evolution of the study area is mainly based on the analysis of three aspects: (1) Residual analysis and acoustic formation thickness of each period is calculated stripping appetite; (2) tectonic evolution of the profile analysis; (3) analysis of tectonic evolution and history of the development. By analyzing the above three aspects, the tectonic evolution of the study area is mainly divided into four stages: early faulted phase (which is from Jurassic period to tongbomiao during the deposition),strongly faulted phase (which is from Nantun period to Damoguaihe deposition period), Off-figuratively transformed in stage (Yimin deposition period), Depression period (Qingyuangang group and the third fourth period sedimentary strata). Passing off the end of the deposition, there is a strong uplift and erosion in this study area, steep slopes and over a large section of the local area denudation exhausted.

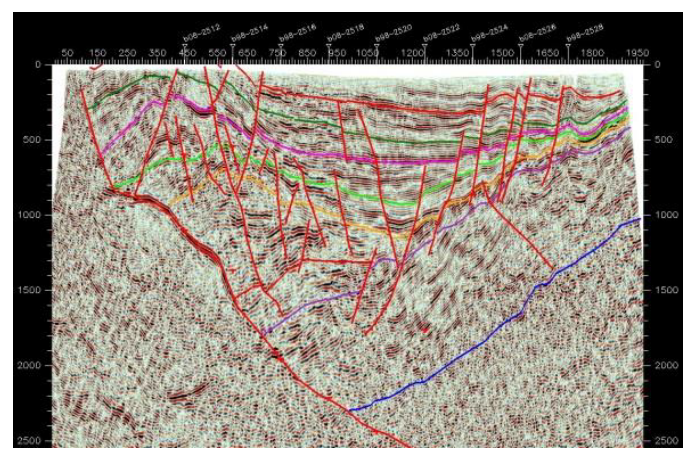

Figure 4. Bayanhushu depression seismic line in 1837

Bayanhushu depression is affected northwestern adun $\mathrm{Chu} \mathrm{Lu}$ fracture control of NE to narrow graben fault, and adun $\mathrm{Chu} \mathrm{Lu}$ depression fracture is located in northwest boundary fracture depression. The fault strikes NE, tendency SE, for shovel section, dipping to 30 to 60 degrees. Going across entire work area from SM to NE, extending the length of more than $100 \mathrm{~km}$, which disconnects the horizon for $\mathrm{J} \sim \mathrm{Q}$, level off from $180 \sim 40 \mathrm{~m}$, and down from $160 \sim 600 \mathrm{~m}$ vertical. From Jurassic to Cretaceous sedimentary lately, adun Chu $\mathrm{Lu}$ fracture sustained activity, control the whole west side of the boundary of the formation and depression scale, as the most important work in the region controlled concave fracture, having earlier formation, inheritance and development characteristics. Bayanhushu experienced depression experienced four tectonic evolution, twice more severe structural inversion, the other region's significant uplift and erosion (Figure 4).

\section{TECTONIC CONTROL ON HYDROCARBON ACCUMULATION}

\subsection{Tectonic evolution of the control of the deposition}

Sedimentary characteristics are mainly controlled by the tectonic evolution of the rift. Rift basin, structural characteristics and evolution of the distribution of oil and gas have an important role to control, and structural features control the deposition, thus control oil output, reservoir, development and distribution of cap and combinations. Structural features control the hydrocarbon migration and accumulation conditions, and then control the distribution of oil and gas. Sedimentary characteristics are different at different stages of evolution of the basin. Rift mainly developed alluvial fan microfacies with coarse sediment grain size at the early stages in small lacustrine range. The fan delta-lake system which is mainly developed in during strongly faulted period on and off-figuratively stages of transformation. It mainly developed fluvial alluvial.

Bayanhushu depression is characterized by the development of sedimentary tectonic subsidence, sediment supply, lake level changes and other factors which are controlled. Experienced early rift, rift strong period, broken-figuratively converted three of the more obvious deposition stage in Tongbomiao Tai Damoguaihe during the deposition, corresponding deposited Tongbomiao fan delta, shallow lake, deep lake-semi-deep lacustrine strata of coarse, Nantun group with deep lake-semi-deep lake, (fan) delta, nearshore subaqueous fan, fan and other fine-grained sedimentary lake, Damoguaihe group with normal delta, shallow lakes, deep lake-semi-deep lake in the coarse sedimentary.

Bayanhushu tectonic-sedimentary sequence is a more typical response process, especially in Tongbomiao,Nantun Formation sedimentary period, gully control performance for the same deposition source faulting valley formed during the multi-directional control sediment source and fan body, fan-delta strike, the study area by drilling and seismic data analysis. This study is the first one in the western side of the 


\section{MATEC Web of Conferences}

fault control transition zone, for Tongbomiao, Nantun group during a period of ancient sedimentary lower parts of the valley, along the valley towards the development of the North Eastern provenance deposition. And favorable structure that matches the sand near the source, favorable hydrocarbon accumulation, prototype basin restoration considered ancient sand distribution channel control, the western and the eastern slope with a gentle slope fan delta with fan delta front sands development, good physical properties, is favorable reservoir distribution. Fan Delta is a favorable reservoir in the western and eastern steep slope with a gentle slope of fan delta front sands development and good physical properties.

\subsection{Structural control on hydrocarbon accumulation}

According stratigraphic circumstances, causes, structure and structural features, Bayanhushu depression is divided into the western slope zone, east gentle slope belt, Banan secongly concave, north Pakistan secondly concave, Pakistan and South sub-concave depression trough, Pakistan and North sub-concave depression trough, Banan uplift, uplift and north Pakistan central low projections 9 tectonic belt. Bayanhushu depression includes Banan, Pakistan, North Pakistan three secondly depression, corresponding to three oil source subsags. These grooves are named from the structure of Bayan Syncline, Yaodaobi syncline and Bayantala syncline. Pakistan second concave groove is the main raw recessed main oil source subsags, North Pakistan Sag subsags oil source for secondary oil generation subsags, with some oil generation capacity but smaller Banan Sag subsags oil source is not complete, although with a syncline form, but oil generation capacity and scale are poor. Bayan syncline is located in the southwest side, and there are two main measuring line in work area and three liaison survey lines through the construction area of $96 \mathrm{~km}^{2}$. Distribution is extremely confined area, Banan secondly sag structure is incomplete, fault is not developed, relatively simple structure. With a small fan delta from the northwest reservoir conditions, the Bayan Syncline subsags oil source is extremely narrow, shallow burial depth of source rocks, the lack of effective source rocks, which can be concluded that no conditions for the formation of hydrocarbon accumulation.

\subsection{Oil and gas distribution}

\subsubsection{Reservoir type}

The area covered in the context of multiple sets of storage portfolio, in order to block the development of stratigraphic pinch-based multiple types of traps and reservoir types, forming a combination of multiple sets of oil; Hydrocarbon groove around the main structure of hydrocarbon enrichment, the groove is hidden reservoir gathering area. Main types of reservoir contain construction, structural - stratigraphic reservoirs in two categories.

\subsubsection{Oil and gas distribution}

(1) Distribution of source subsags mature source rocks hydrocarbon enrichment control range: Range control of hydrocarbon reservoir rock distribution, oil and gas-rich hydrocarbon subsags relative enrichment Bayanhushu depression west fault uneven subsidence control long-term succession caused by faulting size within each sub-concave depression, depth is very different, oil generation capacity subsags obvious differences. Pakistan secondly concave deposition thickness, lacustrine sedimentary development, high abundance of organic matter type, high degree of conversion, Nantun period and Tongbomiao all entered the oil source rocks in the peak period, adequate source of oil, is the main hydrocarbon source area. (2) Sandstone, sandy conglomerate is the major oil and gas reservoirs: Bayanhushu depression reservoir glutenite mainly fan delta reservoir for the best. (3) The main fault zone structure is controlled by the favorable reservoir gathered with: Main fracture referring to the formation of long-term development of earlier and contemporaneous faults controls the deposition of the development, distribution and structural traps forming hydrocarbon source rocks; in its role, the development of multiple sets of reservoir rocks series, favorable oil and gas bearing formation of multiple sets of lines. Superimposed on each other longitudinal and transverse composite contiguous, forming double oil and gas accumulation. By faulting, easy to form a variety of tectonic belt, rift between the gentle slope belt, with steep ridges and grooves with depression are favorable for hydrocarbon accumulation zone.

The area covered in the context of multiple sets of storage portfolio is in order to block the development of stratigraphic pinch-based multiple types of traps and reservoir types, forming a combination of multiple sets of oil; hydrocarbon groove is around the main structure of hydrocarbon enrichment, the groove is hidden in reservoir gathering area. Main types of reservoir are construction, structural-stratigraphic reservoirs in two categories. Bayanhushu depression reservoir is controlled by tectonic movements Nantun group formed by the late inverbasin-tectonics, early structural inversion is helpful for hydrocarbon accumulation, the main types of reservoir include reservoir construction, structural-lithologic reservoir, hydrocarbon enrichment wing inverted structure.

Through comprehensive evaluation, reservoir, cap, circle, transportation, insurance and other factors considered, Bayanhushu depression steep slope with Shu 1 well nose structure, block structure chu 2 jing with a gentle slope with inverbasin-tectonics are favorable exploration zones.

\section{CONCLUSIONS}

(1) In Bayanhushu depression normal faults, most of the faults are consistent with the axial depression, namely NE direction, a small amount of NS, NEE trending faults. The type of fault is mainly a combina- 
tion of Y-shaped and stepped combination;

(2) Depression went through the end of the two-stage Nantun and Yimin reversal of the big changes, reversing earlier favorable changes in the formation of traps, trap with late changes to reverse the damaging effects of early formation, reservoir by the end of the anti-Nantun structure formed by moving the control change, steep wing structure with hydrocarbon accumulation;

(3) Develop three on the lower reservoir and cap, the main types of reservoirs are constructed reservoir, structural-lithologic reservoir, western steep nose structure tectonic belt, Pakistan middle order concave lower projections are Bayanhushu depression favorable exploration zones;

(4) Developing three-reservoir-cap portfolio, the combination of oil and gas accumulation exists in the middle of Nantun group and the lower part of Tongbomiao, the main types of reservoirs contain constructed reservoir, structural - lithologic reservoir. Favorable exploration zones are western steep nose tectonic belt、Pakistan order concave middle lower projections and Pakistan secondly concave ramp with a reverse block development.

\section{REFERENCES}

[1] Zhang Jiguang. 1992. Structural characteristics and hydrocarbon Hailar Basin discussion. Petroleum Geology and Development, 11(1): 14-20.

[2] P.A. Allen, J.R. Allen. 1990. Basinanalysis: Principle and Application. Oxford: Blackwell Scientific Publications, pp: 1-464.

[3] Lu Kezheng, Qi Jiafu. 1997. Cenozoic Bohai Bay Basin Oil and Gas Structures Mode, Beijing: Geological Publishing House, pp: 1-209.

[4] Lu Kezheng, Zhu Xiaomin, Qi Jiafu. 2001. Hydrocarbon Basin. Beijing: Petroleum University Press, pp: 1-424.

[5] Peng Wei, Song Yumei. 2006. Hailar Basin Bayanhushu forming conditions. Acta Petrolei Sinnic, 27(6): 18-22.

[6] Sun Guoxin, Zhang Yajin. 2005. Bayanhushu depression petroleum geology and exploration prospects. Petroleum Geology and Development, 24(3): 82-85.

[7] Chen Junliang, Wu Yonghe. 2007. Tectonic evolution and oil and gas exploration prospects Hailar Basin. Geological Sciences, 42(1): 147-152. 